\title{
$16(2)(2021) 64-77$
}

Teknika

http://journals.usm.ac.id/index.php/teknika

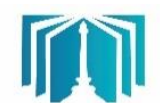

JURNAL ILMIAH

\section{Kajian Penempatan Lokasi Bangunan Pengendali Sedimen (Check Dam) DAS Tapin}

\author{
Rahmawati $^{1^{*}},{\text { Faiqun Ni' } \mathbf{a m}^{2} \text {, Rachmat Mudiyono }}^{3}$ \\ ${ }^{1,2,3}$ Universitas Islam Sultan Agung Semarang, Indonesia
}

\section{Info Artikel}

Sejarah Artikel:

Disubmit 02-11-2021

Publish 30-12-2021

\section{Keywords:}

Arc SWAT; Check dam;

Erosion; Expert choice;

Sedimentation

\begin{abstract}
Abstrak
Sedimen merupakan material yang terbawa hanyut dan bergerak mengikuti arah aliran air sungai dan mengendap di hilir suatu DAS. Perubahan tata guna lahan di hulu DAS berpotensi meningkatkan sedimen. Selain itu, peningkatan jumlah penduduk akan sebanding dengan meningkatnya kebutuhan lahan baik untuk pemukiman maupun pertanian sehingga lahan hutan akan terjarah dan meningkatkan sedimentasi. Untuk mengatasi permasalahan tersebut maka diperlukan kajian penempatan bangunan pengendali sedimen atau check dam. Sedimentasi dipengaruhi oleh erosi. Analisis erosi dan sedimentasi dianalisa menggunakan aplikasi Arc SWAT dengan hasil analisa yaitu erosi DAS Tapin rata-rata pada Kelas Berat yaitu $>180$ ton/ha/tahun. Perubahan nilai sedimentasi dari perencanaan bendungan sampai sekarang yaitu $1.6 \mathrm{~mm} /$ th menjadi $1.8 \mathrm{~mm} / \mathrm{th}$. Analisa pemilihan lokasi check dam menggunakn AHP (Analytical Hierarchy Process) Expert Choice. Dari analisis pemilihan prioritas lokasi check dam dapat diketahui bahwa lokasi yang paling optimal dibangun check dam adalah Sub DAS 1. Analisis debit banjir rancangan untuk Sub DAS 1 pada Q 50 tahun menggunakan metode ITB-2 sebesar $41,34 \mathrm{~m}^{3} /$ detik. Aspek hidrolis check dam pada Sub DAS 1 yaitu dengan disesuikan dengan penampang sungai dari analisis sebelumnya, hasil analisa inflow sedimen sebesar 6.592,05 $\mathrm{m}^{3} /$ tahun dan tampungan kapasitas tampungan 49.132,00 $\mathrm{m}^{3}$ dengan tinggi bangunan 3.75 meter.
\end{abstract}

Alamat Korespondensi:

E-mail: wrahma1809@gmail.com
p-ISSN 1410-4202 e-ISSN 2580-8478 


\section{PENDAHULUAN}

Sedimen dihasilkan dari terbawanya permukaan tanah oleh energi air yang disebut dengan erosi. Besarnya energi hujan, kemiringan lahan, penutupan lahan, jenis tanah serta pengolahan tanah yang ada mempengaruhi besarnya sedimen yang masuk ke dalam sungai. Sedimen tersebut juga akan terjadi di bangunan rekayasa salah satunya bendungan. Sedimen di dalam waduk secara terus menerus akan mengendap dan mempengaruhi lama serta besarnya tampungan bendungan tersebut sesui desain yang sudah direncanakan. Apabila jumlah sedimen yang masuk ke dalam tampungan lebih besar dibanding kapasitas waduknya, maka usia guna waduk akan berkurang dari usia guna yang telah direncanakan (Ma'wa, 2011).

Bendungan Tapin merupakan bendungan yang berada di Desa Pipitak Jaya, Kecamatan Piani, Kabupaten Tapin, Provinsi Kalimantan Selatan. Berdasarkan studi terdahulu tentang Perubahan Tutupan Lahan dan Lingkungan di Provinsi Kalimantan Selatan yang disusun oleh BPPT tahun 2010, terjadi perubahan tata guna lahan di Kalimantan Selatan dari tahun 2004 hingga 2007. Berdasarkan data Badan Statistik Kabupaten Tapin tahun 2019, jumlah penduduk Kabupaten Tapin mengalami pertumbuhan penduduk tiap tahunnya. Kenyataan tersebut memicu alih fungsi lahan yang tidak terkendali karena masyarakat mencari kebutuhan hidupnya salah satunya membuka hutan untuk dijadikan ladang pertanian. Oleh adanya kondisi tersebut perlu adanya upaya untuk menjaga usia guna bendungan sesuai rencana. Salah satu upaya secara teknis adalah dengan Bangunan Pengendali Sedimen (check dam). Check dam digunakan untuk mengatur kemiringan dasar sungai sehingga mencegah terjadinya penggerusan yang membahayakan stabilitas bangunan di sepanjang sungai (Michalec, 2014). Penempatan lokasi tersebut harus tepat sesuai kondisi erosi, slope dan penggunaan lahan yang ada. Berdasarkan penelitian Rusdi (2013), mengatakan bahwa arahan penggunaan lahan yang sesuai dalam menjaga kelestariannya adalah menerapkan tindakan konservasi metode vegetatif dan mekanis (bangunan Sipil).

Tujuan dari kajian ini adalah memprediksi besarnya sedimen dari awal pembangunan Bendungan Tapin (2014) hingga sekarang (2020), menempatkan bangunan pengendali sedimen di lokasi yang sesuai dan efisien sesuai kriteria-kriteria sesuai peraturan yang ada, serta mengkaji aspek hidrolis dari bangunan pengendali sedimen. Berdasarkan laporan sertifikasi pembangunan Bendungan Tapin (Karya, 2014), rencana usia guna bendungan adalah 50 tahun. Oleh karena itu, untuk mencapai tujuan tersebut perlu adanya upaya pengendalian sedimen dengan bangunan pengendali sedimen.

Manfaat yang dapat dicapai dari kajian ini adalah sedimentasi bisa dikendalikan sehingga tidak mengganggu kinerja Bendungan Tapin dengan memberikan rekomendasi kepada Dinas terkait, yaitu penempatan bangunan pengendali sedimen dari hasil analisis.

\section{METODE}

Secara geografis DAS Tapin terletak pada $2^{\circ} 32^{\prime} 43^{\prime \prime}-3^{\circ} 00^{\prime} 43^{\prime \prime}$ LS dan antara $114^{\circ} 46^{\prime} 13^{\prime \prime}-115^{\circ}$ 30'33" BT. Sungai utama dari DAS Tapin adalah Sungai Tapin. Peta lokasi penelelitian terlihat pada Gambar 1. 


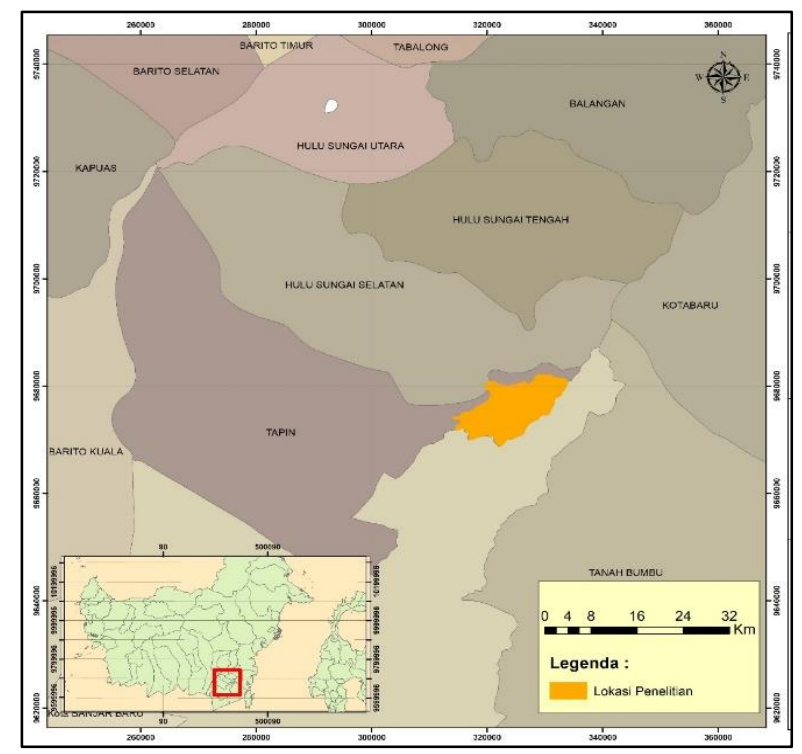

Gambar 1. Peta Lokasi Penelitian

Sumber : Hasil Analisis ArcGIS, 2021

Data-data yang diperlukan :

1. Data primer :

- Data dari anak-anak sungai di DAS Tapin

- Kondisi cross section sungai dan penutupan lahan di DAS Tapin

2. Data sekunder :

- Data curah hujan

- Peta DAS dan Sub DAS

- Peta Jenis Tanah

- Peta kontur DAS Tapin

- Peta Penggunaan lahan

Metode analisis yang dilakukan yaitu :

1. Analisis erosi dan sedimentasi menggunakan aplikasi Arc SWAT. Analisis ini dimulai dengan membuat HRU (Hydrologic Respons Unit) sebagai satuan terkecil unit hidrologi sebagai dasar analisa per titik. Kemudian membuat project di aplikasi kemudian memasukkan parameter seperti curah hujan, slope, jenis tanah, penggunaan lahan dianalisis dengan berbagai parameter di dalamnya. Oleh karena itu, muncul hasil berupa nilai erosi dan sedimentasi per lokasi HRU yang kemudian dikumulatif ke dalam nilai erosi dan sedimentasi per sub DAS.

2. Analisis penetuan lokasi check dam dengan AHP Expert Choice. Prinsip dari analisis ini adalah mendefinisikan masalah ke dalam kelas hirarki. Sehingga lebih mudah dalam pengambilan keputusan. Faktor-faktor yang digunakan dalam pengambilan keputusan ini adalah tingkat erosi, slope dan penggunaan lahan dengan bobot yang berbeda-beda.

3. Analisis debit banjir dengan ITB-2. Sebelum analisis ini, curah hujan dianalisis dispersinya atau persebarannya menggunakan Gumbel, Normal, Log Normal dan Log Pearson tipe III.

4. Aspek hidrolis check dam disesuaikan dengan penampang sungai yang ada. 
Bagan alir dalam penelitian ini dapat dilihat pada Gambar 2.

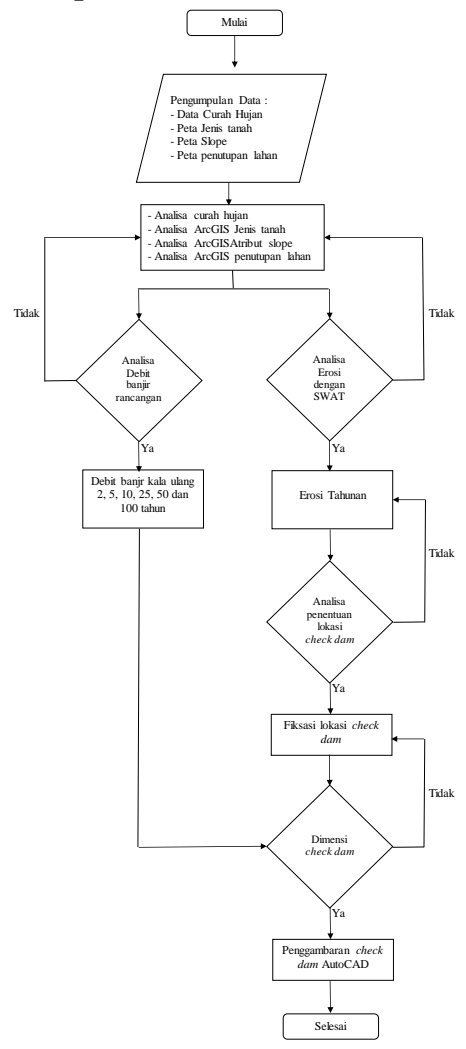

Gambar 2. Bagan Alir

Sumber : Peneliti, 2021

\section{HASIL DAN PEMBAHASAN}

1. Analisis Erosi dengan Arc SWAT

Model ArcSWAT telah digunakan untuk analisa pada DAS Serayu Hulu dengan ketelitian yang akurat (Christanto, 2018). Pada analisis ArcSWAT dasar rumus empiris yang digunakan yaitu USLE (Universal Soil Loss Equation) sebagaimana yang digunakan oleh Kaharuddin (2014) dalam kajiannya untuk laju sedimentasi pada DAS Hulu Batang Gadis, hasil kajiannya menunjukkan bahwa nilai erosi terbesar adalah lokasi yang akan dibangun bangunan pengendali sedimen. Faktor-faktor penyebab erosi dianalisis terlebih dahulu. Hasil analisa slope di DAS Tapin ditunjukkan pada Tabel 1.

Tabel 1. Prosentase DAS Tapin Berdasarkan Kelas Lereng

\begin{tabular}{|c|c|c|c|}
\hline Kelas Lereng & Kemiringan (\%) & Luas $\left(\mathrm{km}^{2}\right)$ & Persentase (\%) \\
\hline Datar & $0-2$ & 1.16 & 0.86 \\
\hline Landai & $2-15$ & 56.96 & 42.32 \\
\hline Agak Curam & $15-25$ & 48.39 & 35.96 \\
\hline Curam & $25-40$ & 27.47 & 20.41 \\
\hline Sangat Curam & $>40$ & 0.59 & 0.44 \\
\hline \multicolumn{2}{|c|}{ Total } & 134.57 & 100.00 \\
\hline
\end{tabular}

Sumber : Hasil Analisis Peneliti, 2021 
Dari Tabel 1 dapat dilihat bahwa kondisi lereng di DAS Tapin sebagian besar landai hingga agak curam. Semakin besar kelerengan maka semakin besar potensi erosi yang terjadi. Selanjutnya analisis jenis tanah yang disajikan dalam bentuk lahan, dimana analisa ini dilakukan di aplikasi Arc SWAT dengan penentuan nilai erodibilitas tanah (K). Kepekaan tanah terhadap erosi, atau erodibilitas tanah dapat didefinisikan sebagai mudah tidaknya suatu tanah untuk dihancurkan oleh kekuatan jatuhnya butir-butir hujan, atau oleh kekuaatan aliran permukaan (Sulistyaningrum, 2013). Semakin besar nilai $\mathrm{K}$ maka semakin peka terhadap erosi atau potensi erosi semakin besar. Hasil analisa karakteristik tanah di DAS Tapin dengan parameter erodibilitas tanah ditunjukkan pada Tabel 2.

Tabel 2. Karakteristik Fisik Tanah di DAS Tapin

\begin{tabular}{lcc}
\hline \multicolumn{1}{c}{ Bentuk lahan } & Bulk Density $\left(\mathrm{g} / \mathrm{cm}^{3}\right)$ & Erodibilitas \\
\hline Lereng Bawah & 1.02 & 0.50 \\
Lereng tengah & 1.02 & 0.49 \\
Puncak & 1.04 & 0.50 \\
Lereng atas & 1.03 & 0.49 \\
Dataran & 1.02 & 0.49 \\
\hline \multicolumn{3}{c}{ Sumber : Hasil Analisis Peneliti, 2021 }
\end{tabular}

Dari Tabel 2 dapat dilihat bahwa DAS Tapin mempunyai nilai K 0.50 jika masuk ke dalam klasifikasi nilai K 0.50 termasuk dalam klasifikasi relatif tinggi, artinya cukup potensi besar menyebabkan erosi. Analisis selanjutnya yaitu penutupan lahan di DAS Tapin. Hasil analisa penggunaan lahan di DAS Tapin ditunjukkan pada Tabel 3.

Tabel 3. Prosentase Penggunaan Lahan DAS Tapin

\begin{tabular}{|c|c|c|c|}
\hline No & Penggunaan Lahan & Luas $\left(\mathrm{km}^{2}\right)$ & Persentase \\
\hline 1 & Hutan Primer & 22.407 & 16.651 \\
\hline 2 & Hutan Sekunder & 87.670 & 65.150 \\
\hline 3 & Jalan & 0.420 & 0.312 \\
\hline 4 & Pemukiman & 0.267 & 0.199 \\
\hline 5 & Perkebunan & 0.252 & 0.187 \\
\hline 6 & Sawah & 1.415 & 1.052 \\
\hline 7 & Semak/Belukar & 18.131 & 13.473 \\
\hline 8 & Tegalan & 3.480 & 2.586 \\
\hline \multirow[t]{2}{*}{9} & Tubuh Air & 0.524 & 0.389 \\
\hline & Total & 134.568 & 100 \\
\hline
\end{tabular}

Dari Tabel 3 dapat dilihat bahwa prosentase terbesar penggunaan lahan di DAS Tapin adalah hutan sekunder. Semakin terbuka suatu lahan maka semakin besar potensi erosi yang terjadi. Kurangnya tanaman pelindung di area terbuka menyebabkan hilangnya penahan air dan menurunkan kemampuan tanah meresapkan air sehingga menyebabkan besarnya aliran permukaan dan erosi yang kemudian membawa sedimen masuk ke aliran sungai sampai terendapkan di outlet DAS (Wahdani, 2011). Analisis erosi menggunakan ArcSWAT dengan dasar HRU dan selanjutnya diakumulasikan 
per sub DAS. Hasil analisis erosi diklasifikasikan ke dalam beberapa kelas yaitu sangat ringan hingga sangat berat sesuai Tabel 4.

Tabel 4. Kelas Bahaya Erosi

\begin{tabular}{ccc}
\hline $\begin{array}{c}\text { Kelas Bahaya } \\
\text { Erosi }\end{array}$ & $\begin{array}{c}\text { Laju Erosi (E-Akt) } \\
\text { (ton/ha/thn) }\end{array}$ & Harkat \\
\hline I & $<15$ & Sangat Ringan \\
II & $15-60$ & Ringan \\
III & $60-180$ & Sedang \\
IV & $180-480$ & Berat \\
V & $>480$ & Sangat Berat \\
\hline Sumber: United States Department of Agriculture (USDA) dalam Huda, 2020
\end{tabular}

Hasil analisis erosi setiap Sub DAS di DAS Tapin ditunjukkan pada Tabel 5.

Tabel 5. Nilai erosi di setiap Sub DAS Tapin

\begin{tabular}{|c|c|c|}
\hline Nomor Sub DAS & Erosi (Ton/Ha/Th) & Kelas Erosi \\
\hline 1 & 427.404 & Berat \\
\hline 2 & 235.898 & Berat \\
\hline 3 & 185.129 & Berat \\
\hline 4 & 425.709 & Berat \\
\hline 5 & 200.422 & Berat \\
\hline 6 & 163.964 & Sedang \\
\hline 7 & 227.073 & Berat \\
\hline 8 & 229.565 & Berat \\
\hline 9 & 145.601 & Sedang \\
\hline 10 & 239.869 & Berat \\
\hline 11 & 137.537 & Sedang \\
\hline 12 & 148.827 & Sedang \\
\hline 13 & 302.386 & Berat \\
\hline 14 & 254.888 & Berat \\
\hline 15 & 287.190 & Berat \\
\hline 16 & 218.103 & Berat \\
\hline 17 & 301.334 & Berat \\
\hline 18 & 219.100 & Berat \\
\hline 19 & 315.503 & Berat \\
\hline 20 & 196.405 & Berat \\
\hline 21 & 238.664 & Berat \\
\hline 22 & 284.635 & Berat \\
\hline 23 & 161.746 & Sedang \\
\hline 24 & 384.859 & Berat \\
\hline 25 & 384.067 & Berat \\
\hline
\end{tabular}

Sumber : Hasil Analisis Peneliti, 2021 
Dari Tabel 5 dapat dilihat bahwa nilai erosi di DAS Tapin sebagian besar termasuk dalam kelas berat yaitu dengan nilai erosi $>180$ ton/ha/tahun. Grafik besarnya erosi dapat dilihat Gambar 3.

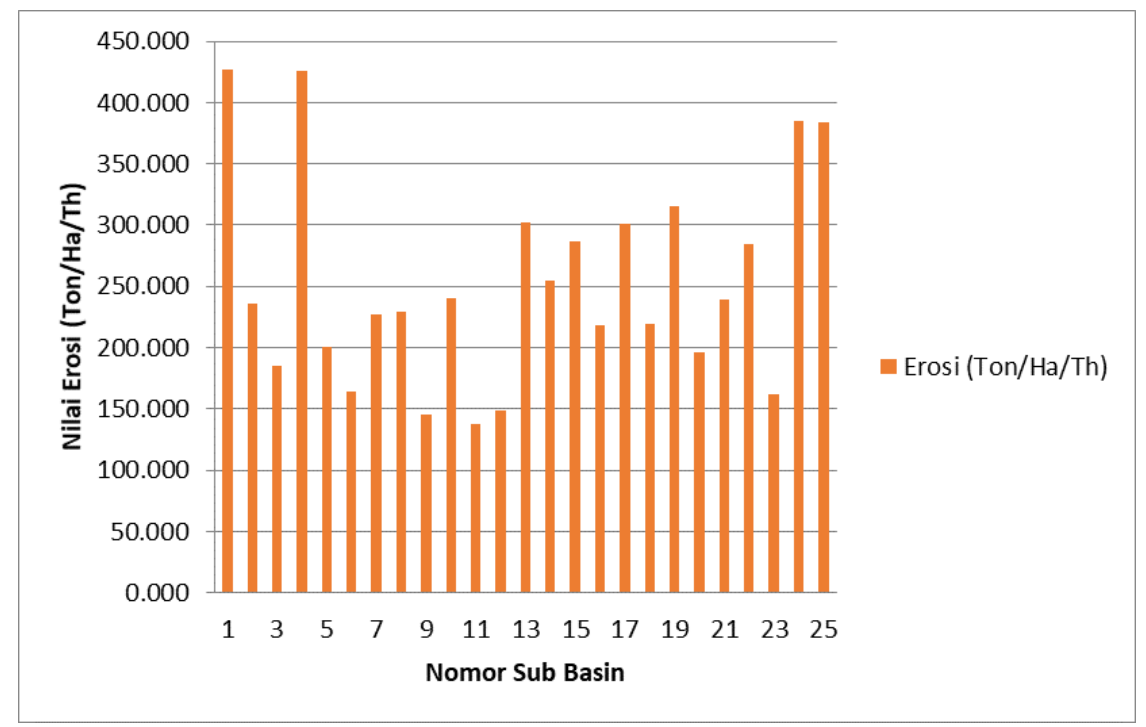

Gambar 3. Grafik Nilai Erosi per Sub DAS

Sumber : Hasil Analisis Peneliti, 2021

Hasil analisa persebaran erosi setiap Sub DAS di DAS Tapin dilihat pada Gambar 4.

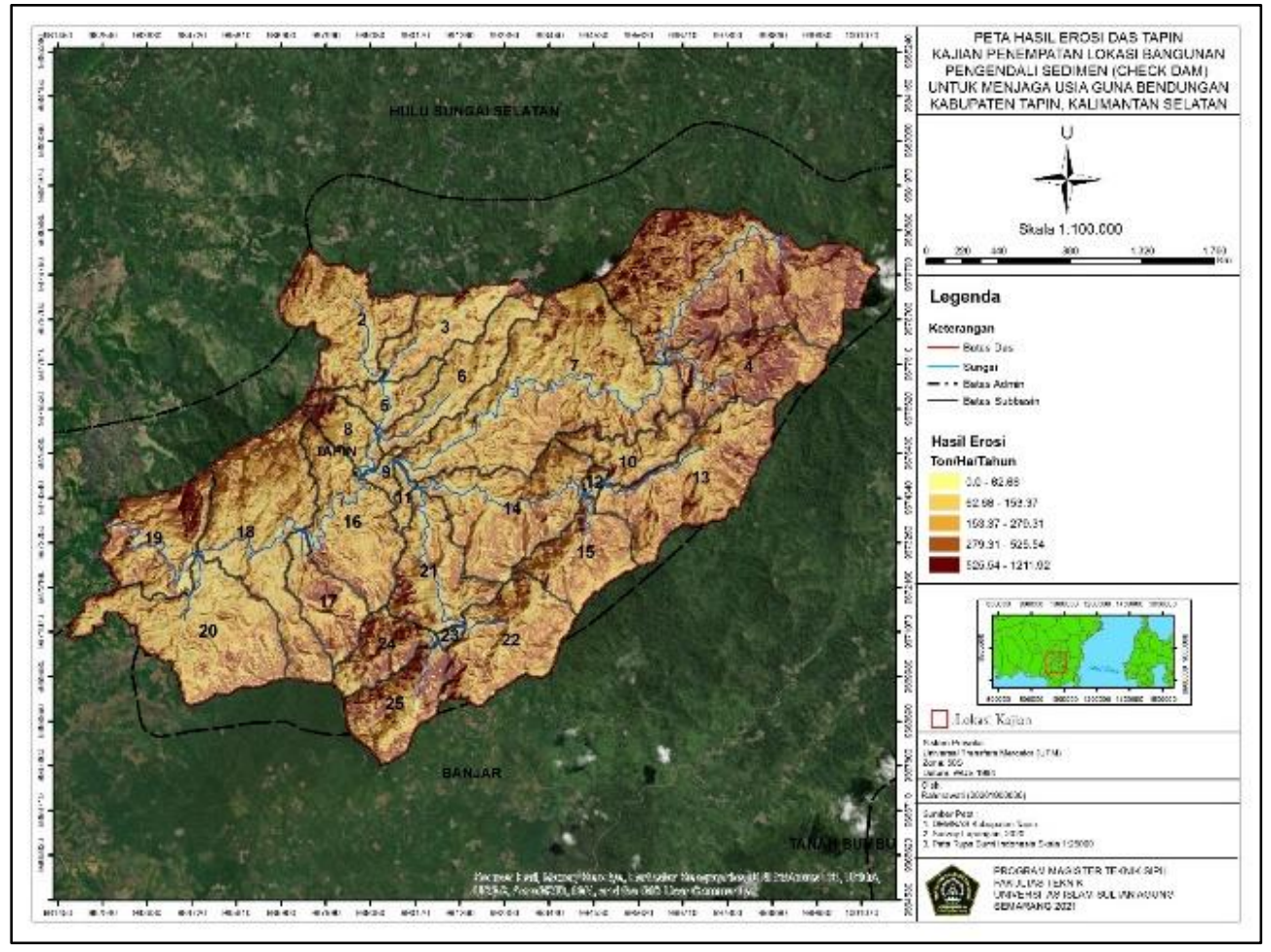

Gambar 4. Peta Persebaran Erosi DAS Tapin

Sumber : Hasil Analisis ArcGIS, 2021 
2. Analisiis Pemilihan Lokasi dengan AHP Expert Choice

Metode AHP juga pernah digunakan untuk analisis pemilihan kantor dengan pembobotan yang berbeda setiap parameter sesuai dengan kepentingannya (Fauzan, 2016). Metode AHP akan menjelaskan masalah dengan multi faktor dan multi kriteria yang kompleks disusun menjadi satu hirarki (Magdalena, 2012). Berdasarkan Utomo, (2018), bahwa penentuan lokasi dam penahan berdasarkan pada tingkat erosi, luas daerah tangkapan 10-30 Ha, kemiringan lereng 15-35\% dan tutupan lahan bukan pemukiman. Pembobotan untuk pengambilan keputusan dengan Expert Choice adalah tingkat erosi $50 \%$, slope $30 \%$ dan penutupan lahan $20 \%$. Parameter yang digunakan untuk analisa AHP ditunjukkan pada Tabel 6.

Tabel 6. Parameter Penentuan Lokasi Check Dam

\begin{tabular}{cll}
\hline No. & Uraian & Kriteria Penilaian \\
\hline a & Tingkat Erosi & Sangat berat \\
& & Berat \\
& & Sedang \\
& Ringan \\
& & Sangat ringan \\
\hline b & Tutupan lahan & Lahan terbuka \\
& & Padang rumput \\
& & Semak belukar \\
& & Hutan sekunder \\
& & Hutan Primer \\
\hline c & Slope & $>45$ \\
& & $30-45$ \\
& & $15-30$ \\
& & $<-15$ \\
& & $<8$ \\
\hline
\end{tabular}

Sumber : Peraturan Dirjen DAS, 2013

Pemilihan lokasi penempatan bangunan pengendali sedimen untuk tingkat erosi yang berat pada setiap sub DAS. Hasil analisis Expert Choice dapat dilihat pada Tabel 7.

Tabel 7. Parameter Sub DAS untuk Analisa Expert Choice

\begin{tabular}{ccll}
\hline Nomor Sub DAS & Erosi (Ton/Ha/Th) & $\begin{array}{l}\text { Prosentase terbesar } \\
\text { penggunaan lahan }\end{array}$ & Slope (\%) \\
\hline 1 & 427.404 & Hutan sekunder & 18.14 \\
2 & 235.898 & Hutan sekunder & 17.35 \\
3 & 185.129 & Hutan sekunder & 8.80 \\
4 & 425.709 & Hutan Primer & 13.56 \\
5 & 200.422 & Hutan Sekunder & 12.85 \\
7 & 227.073 & Hutan sekunder & 14.60 \\
8 & 229.565 & Hutan Primer & 10.45
\end{tabular}




\begin{tabular}{ccll}
\hline Nomor Sub DAS & Erosi (Ton/Ha/Th) & $\begin{array}{l}\text { Prosentase terbesar } \\
\text { penggunaan lahan }\end{array}$ & Slope (\%) \\
\hline 10 & 239.869 & Hutan sekunder & 19.04 \\
13 & 302.386 & Semak belukar & 24.16 \\
14 & 254.888 & Hutan sekunder & 23.58 \\
15 & 287.190 & Hutan primer & 15.30 \\
16 & 218.103 & Hutan sekunder & 20.88 \\
17 & 301.334 & Semak belukar & 22.06 \\
18 & 219.100 & Hutan sekunder & 21.01 \\
19 & 315.503 & Hutan sekunder & 24.70 \\
20 & 196.405 & Hutan primer & 20.56 \\
21 & 238.664 & Hutan primer & 18.47 \\
22 & 284.635 & Hutan sekunder & 17.42 \\
24 & 384.859 & Semak belukar & 18.57 \\
25 & 384.067 & Semak belukar & 20.35 \\
\hline
\end{tabular}

Parameter-parameter yang tertera pada Tabel 7 diinput ke dalam aplikasi kemudian dibandingkan antar sub DAS sehingga dengan 3 parameter tersebut dapat diperoleh bobot masing-masing sub DAS dan kemudian dapat dirangking prioritas penempatan lokasi check dam. Grafik hasil analisis Expert Choice tertera pada Gambar 5 sedangkan urutan prioritas lokasi check dam dapat dilihat pada Tabel 8.

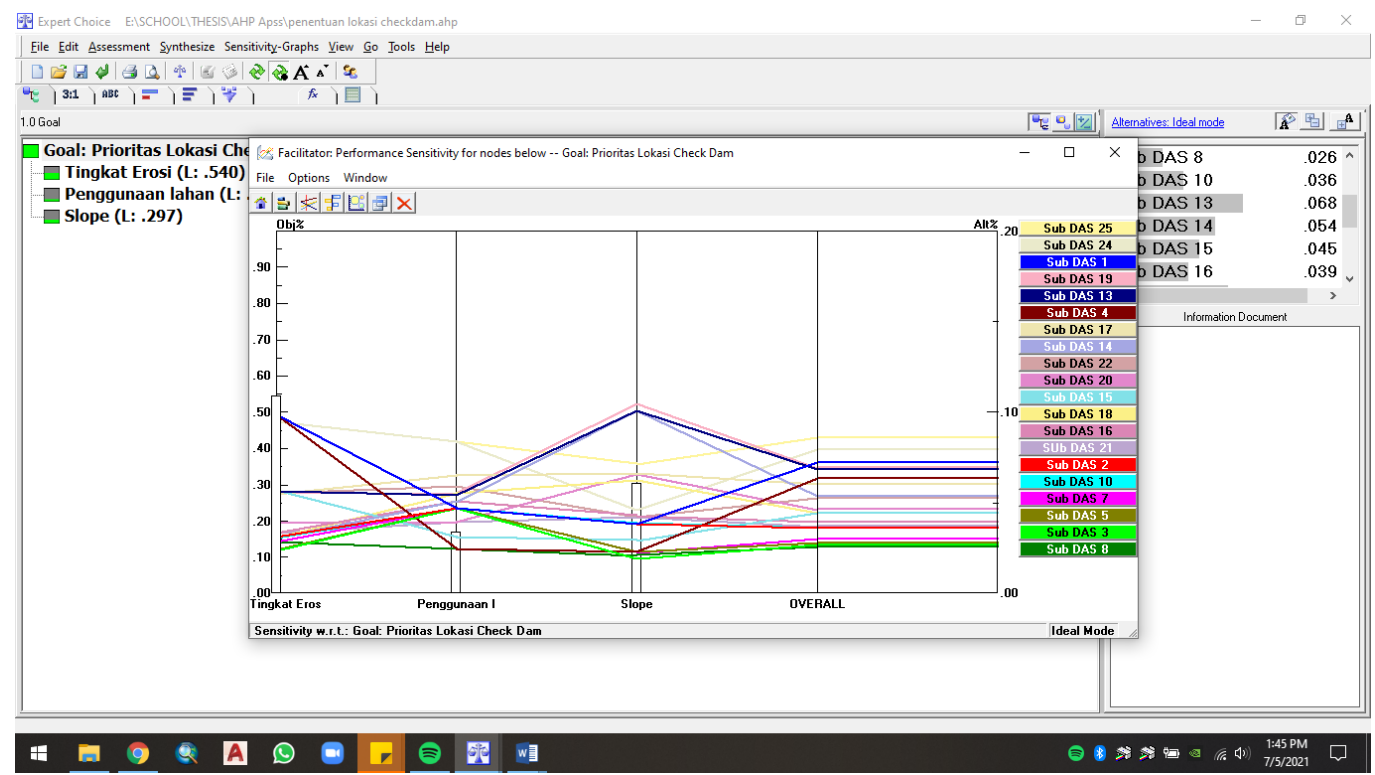

Gambar 5. Grafik Hasil Analisis Expert Choice

Sumber : Hasil Analisis Peneliti, 2021 
Tabel 8. Urutan Prioritas Lokasi Check Dam

\begin{tabular}{clc}
\hline Rangking & \multicolumn{1}{c}{ Nomor Sub DAS } & Bobot (\%) \\
\hline 1 & Sub DAS 25 & 8.6 \\
2 & Sub DAS 24 & 7.9 \\
3 & Sub DAS 1 & 7.2 \\
4 & Sub DAS 19 & 6.9 \\
5 & Sub DAS 13 & 6.8 \\
6 & Sub DAS 4 & 6.4 \\
7 & Sub DAS 17 & 6.0 \\
8 & Sub DAS 14 2.4 \\
9 & Sub DAS 22 & 5.3 \\
10 & Sub DAS 20 & 4.6 \\
11 & Sub DAS 15 & 4.5 \\
12 & Sub DAS 18 & 4.4 \\
13 & Sub DAS 16 & 3.9 \\
14 & Sub DAS 21 & 3.7 \\
15 & Sub DAS 2 & 3.6 \\
16 & Sub DAS 10 & 3.6 \\
17 & Sub DAS 7 & 3.0 \\
18 & Sub DAS 5 & 2.8 \\
19 & Sub DAS 3 & 2.7 \\
20 & Sub DAS 8 & 2.6 \\
\hline & Sumber : Hasil Analisis Peneliti, 2021
\end{tabular}

Gambar 5 dan Tabel 8 menunjukkan hasil analisis Expert Choice dalam bentuk ranking, dari analisis tersebut dapat diketahui bahwa prioritas check dam pada 5 ranking teratas untuk dibangun yaitu pada Sub DAS 25, Sub DAS 24, Sub DAS 1, Sub DAS 19 dan Sub DAS 13. Ranking Sub DAS tersebut dapat dilihat pada Tabel 9.

Tabel 9. Luas Sub DAS 5 Ranking Teratas

\begin{tabular}{clc}
\hline No & Nomor Sub DAS & Bobot (\%) \\
\hline 1 & Sub DAS 25 & 4.05 \\
2 & Sub DAS 24 & 2.78 \\
3 & Sub DAS 1 & 16.04 \\
4 & Sub DAS 19 & 5.42 \\
5 & Sub DAS 13 & 7.89 \\
\hline \multicolumn{3}{c}{ Sumber : Hasil Analisis Peneliti, 2021 }
\end{tabular}

Pada buku Manual Rancang Bangun KTA Kementerian Kehutanan (2015), menyebutkan bahwa bangunan pengendali sedimen dibangun pada daerah tangkapan yang lebih besar sehingga besaran sedimen yang tertampung juga semakin banyak. Dengan demikian perlindungan terhadap bendungan di hilir DAS lebih optimal. Dari Tabel 9 menunjukkan bahwa Sub DAS terbesar adalah Sub DAS 1, oleh karena itu saran untuk dinas yang berwenang terkait lokasi paling optimal untuk dibangun check dam adalah pada Sub DAS 1. 
3. Analisis debit banjir dengan ITB-2

Analisis debit banjir diawali dengan analisa dispersi curah hujan. Sebagai contoh yang dianalisis debit banjirnya adalah sub DAS 1. Hasil analisis dispersi curah hujan dapat dilihat pada Tabel 10.

Tabel 10. Tabel Persyaratan Metode Sebaran

\begin{tabular}{cccc}
\hline Distribusi & Parameter & Hasil Perhitungan & Kesimpulan \\
\hline \multirow{2}{*}{ Normal } & $\mathrm{Cs} \approx 0$ & 0.882 & Tidak \\
& $\mathrm{Ck} \approx 3$ & 3.434 & memenuhi \\
\hline \multirow{2}{*}{ Gumbel } & $\mathrm{Cs} \approx 1.139$ & 0.882 & Tidak \\
& $\mathrm{Ck} \approx 5.402$ & 3.434 & memenuhi \\
\hline \multirow{2}{*}{ Log } & $\mathrm{Cs} \approx 1.137$ & 0.457 & Tidak \\
Normal & $\mathrm{Cv} \approx 0.06$ & 0.038 & memenuhi \\
& $\mathrm{Cs} / \mathrm{Cv}=3$ & 11.98 & \\
\hline Log & Tidak ada & 0.457 & Memenuhi \\
Pearson III & batasan & 0.038 & \\
\hline
\end{tabular}

Sumber : Hasil Analisis Peneliti, 2021

Dari Tabel 10 dapat dilihat bahwa metode Log Pearson adalah yang digunakan untuk analisis selanjutnya. Analisis selanjutnya yaitu sebaran hujan dengan berbagai kala ulang yaitu 2, 5, 10 , 25, 50 dan 100 tahun dapat dilihat pada Tabel 11.

Tabel 11. Perhitungan Sebaran Hujan Metode Log Pearson Type III

\begin{tabular}{cccc}
\hline No & $\begin{array}{c}\text { T } \\
(\text { Tahun })\end{array}$ & $\begin{array}{c}\mathrm{k} \\
\text { Log Person III }\end{array}$ & $\begin{array}{c}\mathrm{Xt} \\
(\mathrm{mm})\end{array}$ \\
\hline 1 & 2 & -0.076 & 109.337 \\
2 & 5 & 0.811 & 128.203 \\
3 & 10 & 1.320 & 140.463 \\
4 & 25 & 1.897 & 155.776 \\
5 & 50 & 2.289 & 167.138 \\
6 & 100 & 2.655 & 178.481 \\
\hline
\end{tabular}

Sumber : Hasil Analisis Peneliti, 2021

Karakeristik DAS debit banjir dapat dilihat pada Tabel 12.

Tabel 12. Karakteristik DAS untuk Analisis Debit Banjir

\begin{tabular}{lllll}
\hline I. Karakteristik DAS dan Hujan & & & \\
\hline 1 & Nama Sub DAS & $=$ & Sub DAS 1 & \\
2 & Luas Daerah Aliran Sungai (Adas) & $=$ & 16.040 & $\mathrm{~km}^{2}$ \\
3 & Panjang Sungai Utama (L) & $=$ & 7.229 & $\mathrm{~km}$ \\
4 & Kemiringan Sungai (S) & $=$ & 1.886 & \\
5 & Tinggi Hujan Satuan (R) & $=$ & 1.000 & $\mathrm{~mm}$ \\
6 & Durasi Hujan Satuan (Tr) & $=$ & 1.000 & $\mathrm{Jam}$ \\
\hline II. Perhitungan Waktu Puncak (Tp) Dan Waktu Dasar (Tb) & \\
\hline 1 & Koefisien waktu (Ct) & $=1.000$ & \\
2 & Time Lag (TL) & & \\
& $\mathrm{TL}=\mathrm{Ct}^{*} 0.21^{*} \mathrm{~L}^{\wedge} 0.7 ; \mathrm{L}<15 \mathrm{~km}$ & $=\mathrm{L}<15 \mathrm{~km}$ & $0.839 \mathrm{jam}$
\end{tabular}




\begin{tabular}{|c|c|c|c|c|}
\hline \multirow{5}{*}{$\begin{array}{l}3 \\
4\end{array}$} & \multicolumn{4}{|l|}{$\begin{array}{l}\mathrm{TL}=\mathrm{Ct}^{*}\left(0.527+0.058^{\star} \mathrm{L}\right) ; \mathrm{L} \geq 15 \mathrm{~km} \\
\text { Waktu Puncak }\end{array}$} \\
\hline & $\mathrm{TP}=1.6 \mathrm{TL}$ & $=$ & 1.342 & Jam \\
\hline & Waktu Dasar & & & \\
\hline & $\mathrm{TB} / \mathrm{TP}$ & $=$ & 20.00 & (Ratio TB/TP) \\
\hline & $\mathrm{TB}$ & $=$ & 26.84 & Jam \\
\hline \multicolumn{5}{|c|}{ III. Debit Puncak (QP) } \\
\hline 1 & Cp. Koefisien Puncak (Cp) & $=$ & 1.000 & \\
\hline 2 & Alpha & $=$ & 2.500 & \\
\hline 3 & Betha & $=$ & 0.720 & \\
\hline 4 & Luas HSS (lihat Bag-IV,Jumlah Kol-4 ) & $=$ & 1.766 & \\
\hline 5 & $\mathrm{Qp}=1 /\left(3.6^{*} \mathrm{Tp}\right)^{*}(\mathrm{ADAS} / \mathrm{AHSS})$ & $=$ & 1.880 & $\mathrm{~m}^{3} / \mathrm{s}$ \\
\hline 6 & Volume Hujan (VDAS $\left.=\mathrm{R}^{*} \mathrm{ADAS} * 1000\right)$ & $=$ & 16040 & $\mathrm{~m}^{3}$ \\
\hline 7 & VHSS (Bag IV, Jumlah kolom-6) & $=$ & 16040 & $\mathrm{~m}^{3}$ \\
\hline 8 & $\mathrm{DRO}=\mathrm{VHSS} / \mathrm{ADAS} / 1000$ & $=$ & 1.000 & $\mathrm{~mm}$ \\
\hline
\end{tabular}

Hasil perhitungan debit banjir menggunakan ITB-2 sub DAS 1 dapat dilihat pada Tabel 13.

Tabel 13. Hasil Analisis Debit Banjir

\begin{tabular}{|c|c|}
\hline $\begin{array}{c}\text { Kala ulang } \\
\text { (tahun) }\end{array}$ & $\begin{array}{c}\text { Debit banjir } \\
\text { maksimum } \\
\mathrm{m}^{3} / \text { detik }\end{array}$ \\
\hline 2 & 27.044 \\
\hline 5 & 31.710 \\
\hline 10 & 34.743 \\
\hline 25 & 38.530 \\
\hline 50 & 41.341 \\
\hline 100 & 44.146 \\
\hline
\end{tabular}

Sumber : Hasil Analisis Peneliti, 2021

Aspek hidrolis check dam yang digunakan untuk desain adalah debit banjir dengan kala ulang 50 tahun.

4. Aspek Hidrolis check dam

Desain check dam yang digunakan adalah desain tipikal dengan aspek hidrolis disesuaikan dengan penampang melintang hasil pengukuran topografi dari studi yang sudah ada. Lokasi Sub DAS 1 terletak pada koordinat 324892,95 E ; 9677572,92 N ; UTM 50S. Lokasi Check dam dapat dilihat pada Gambar 6.

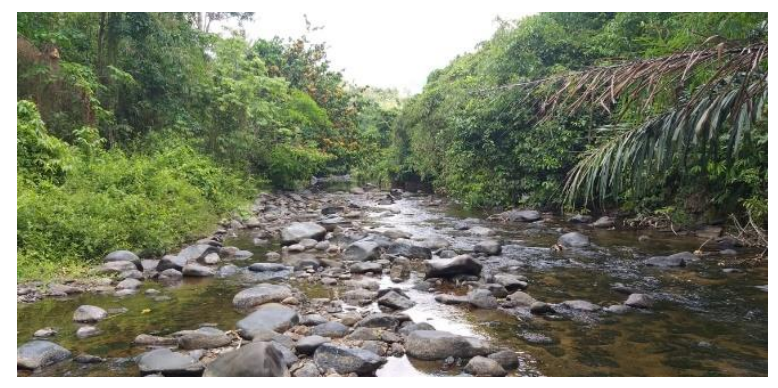

Gambar 6. Penampang Melintang Sungai Sumber : Dokumentasi Peneliti, 2021 
Pada Gambar 6 merupakan lokasi penelitian yang mempunyai lebar sungai $13 \mathrm{~m}$, kondisi lereng agak curam, banyak tersebar material batuan, pada sisi kiri sungai terdapat pemukiman warga dengan jarak $50 \mathrm{~m}$ dari bibir sungai, sisi kanan terdapat kawasan hutan. Gambar tipikal desan bangunan pengendali sedimen dapat dilihat pada Gambar 7.

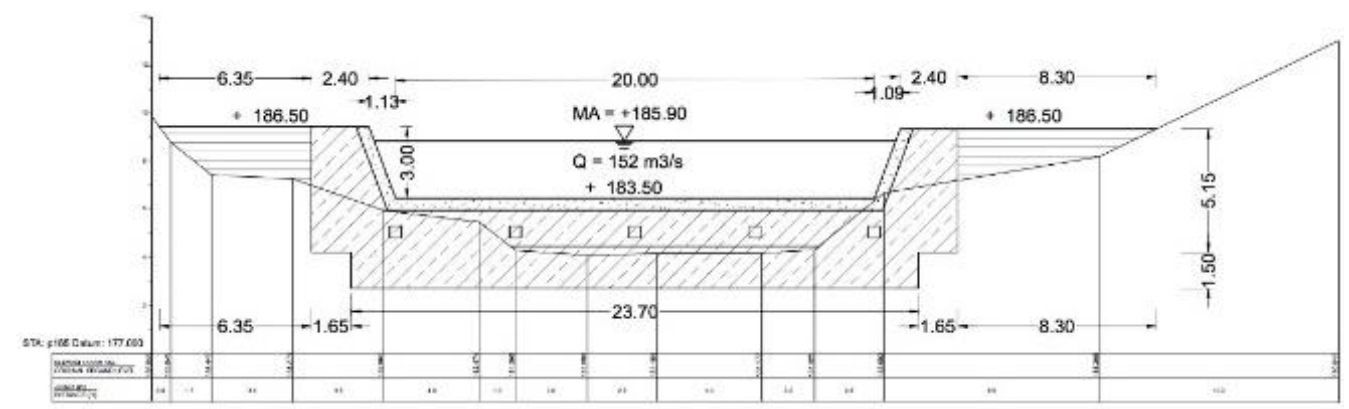

Gambar 7. Dimensi check dam Sesuai dengan Dimensi Sungai

Sumber : Peneliti, 2021

Secara detail penjelasan aspek hidrolis bangunan check dam ditunjukkan pada Tabel 13.

Tabel 13. Hasil Analisis Debit Banjir

Tipe Bangunan

Luas Tangkapan BPS

Laju Sedimentasi Rerata

Sediment Inflow

Kapasitas Tampungan

Tinggi Bangunan

Elevasi Ambang Pelimpah

Lebar Ambang Pelimpah

Panjang Kolam Olak

Q50th

$\begin{aligned}: & \text { Beton } \\ : & 16.04 \mathrm{~km}^{2} \\ : & 0.4 \mathrm{~mm} / \mathrm{th} \\ : & 6.592,05 \mathrm{~m}^{3} / \text { th } \\ : & 49.132,00 \mathrm{~m}^{3} \\ : & 3,75 \mathrm{~m} \\ : & +183,50 \mathrm{~m} \\ : & 20,00 \mathrm{~m} \\ : & 13,00 \mathrm{~m} \\ : & 41.34 \mathrm{~m}^{3} / \text { det }\end{aligned}$

Sumber : Peneliti, 2021

Dengan adanya bangunan ini, maka sebagian dari nilai sedimentasi yang masuk ke dalam waduk dapat dikurangi.

\section{SIMPULAN}

Berdasarkan analisa kajian yang sudah dilakukan dapat disimpulkan bahwa :

1. Erosi dan sedimentasi dipengaruhi oleh beberapa faktor yaitu curah hujan, penutupan lahan, slope dan jenis tanah. Erosi pada DAS Tapin rata-rata termasuk dalam kelas berat yaitu lebih dari 180 ton/ha/tahun. Pada awal perencanaan Bendungan Tapin pada tahun 2014 nilai sedimentasinya 1,60 $\mathrm{mm} /$ th sedangkan analisa saat tahun 2020 mencapai $1.80 \mathrm{~mm} /$ th dari hasil studi terdahulu.

2. Bangunan pengendali sedimen ditempatkan pada lokasi yang sesuai dengan kriteria yaitu dilihat dari parameter tingkat erosi, penggunaan lahan dan slope. Lokasi paling optimal untuk dibangun check dam adalah pada Sub DAS 1. Tingkat erosi pada sub DAS tersebut termasuk berat, dengan penutupan lahan semak belukar dan hutan sekunder serta slope antara $18-20 \%$.

3. Aspek hidrolis check dam Sub DAS 1 dengan desain tipikal adalah sebagai berikut:: dengan tipe bangunan beton, luas tangkapan BPS $16.04 \mathrm{~km}^{2}$, laju sedimentasi rerata $0.4 \mathrm{~mm} /$ th, sedimen inflow 
$6.592,05 \mathrm{~m}^{3} /$ th, kapasitas tampungan $49.132,00 \mathrm{~m}^{3}$, tinggi bangunan $3,75 \mathrm{~m}$, elevasi ambang, Q50th $41.34 \mathrm{~m}^{3} /$ det pelimpah.

\section{DAFTAR PUSTAKA}

Badan Standarisasi Nasional .2015. Desain Bangunan Penahan Sedimen SNI 2851:2015. Standar Nasional Indonesia.

Buku Manual Rancang Bangun KTA Kementerian Kehutanan. 2015.

Christanto, N. 2018. Analisis Laju Sedimen DAS Serayu Hulu dengan Menggunakan Model SWAT. Yogyakarta : Universitas Gadjah Mada.

Fauzan, A. 2016. Analisis Pemilihan Lokasi Kantor Dan Workshop Baru Menggunakan Metode AHP Pada CV. Young Interior. Malang : Institut Teknologi Nasional Malang.

Huda, A.S. 2020. Analisis Perubahan Laju Erosi Periode Tahun 2013 Dan Tahun 2018 Berbasis Data Pengindraan Jauh Dan Sistem Informasi Geografis (Studi Kasus : Das Garang). Semarang Fakultas Teknik Universitas Diponegoro.

Kaharuddin, 2014. Kajian Pengendali Laju Sedimen dengan Baunan Pengendali di DAS Hulu Batang Gadis Propinsi Sumatera Utara. Malang: Program Magister Teknik Pengairan Universitas Brawijaya.

Ma'wa, J. 2011. Studi Pendugaan Sisa Usia Guna Waduk Sengguruh Dengan Pendekatan Erosi Dan Sedimentasi. Malang: Universitas Brawijaya.

Magdalena, H. 2012, Seminar Nasional "Teknologi Informasi dan Komunikasi . Pangkalpinang : STMIK Atma Luhur.

Michalec, B. 2014. Penilaian Distribusi Sedimen pada Kolam Penampungan Kecil. Yogyakarta : UGM.

Peraturan Dirjen DAS, 2013. Peraturan Direktur Jenderal Bina Pengelolaan Daerah Aliran Sungai Dan Perhutanan Sosial Nomor P. 3/V-Set/2013 Tahun 2013.

Rusdi., A. 2013. Degradasi Lahan Akibat Erosi pada Areal Pertanian di Kecamatan Lembah Seulawah Kabupaten Aceh Besar. Jakarta : Manajemen Sumberdaya Lahan.

Sulistyaningrum, D., L. D. Susanawati, \&B. Suharto. 2013. Pengaruh Karakteristik Fisika Kimia Tanah Terhadap Nilai Indeks Erodibilitas Tanah dan Upaya Konservasi Lahan. Jurnal Sumberdaya Alam dan lingkungan. Keteknikan Pertanian. Universitas Brawijaya. Malang

Utomo, T. 2018. Analisis Penentuan Lokasi DAM Penahan Sedimen (DPN) Berdasarkan Tingkat Bahaya Erosi dengan Program Arc GIS. Samarinda: Program Magister Ilmu Kehutanan, Universitas Mulawarman.

Virama Karya. 2014. Sertifikasi Pembangunan Bendungan Tapin.

Wahdani, K. D. 2011. Perkiraan Debit Sungai dan Sedimentasi Dengan Model MWSWAT Di Sub-DAS Citarum Hulu, Provinsi Jawa Barat. Tesis. Sekolah Pascasarjana. IPB. Bogor. 